\title{
Eating Behavior in Rats Subjected to Vagotomy, Sleeve Gastrectomy, and Duodenal Switch
}

\author{
Yosuke Kodama $\cdot$ Chun-Mei Zhao $\cdot$ Bård Kulseng • \\ Duan Chen
}

Received: 26 April 2010 /Accepted: 9 August 2010/Published online: 8 September 2010

(C) 2010 The Author(s). This article is published with open access at Springerlink.com

\begin{abstract}
Background/Aim Food intake, eating behavior, and metabolic parameters in rats that underwent bilateral truncal vagotomy, sleeve gastrectomy, and duodenal switch procedures were examined.

Methods Rats were subjected to bilateral truncal vagotomy plus pyloroplasty (VTPP), pyloroplasty (PP), laparotomy, sleeve gastrectomy (SG), or duodenal switch (DS; with and without SG).

Results VTPP, but neither PP nor laparotomy, reduced body weight (BW; 10\%) transiently (1 week postoperatively). SG reduced BW (10\%) for 6 weeks, while DS alone or SG followed by DS led to a continuous BW loss from $15 \%$ at 1 week to $50 \%$ at 8 weeks postoperatively. Food intake was higher and the satiety ratio was lower during the night than the day for all groups of surgeries. Neither VTPP nor SG had measurable effect on food intake, eating behavior and metabolic parameters. DS reduced daily food intake by more than $50 \%$, which was associated with hypercholecystokinin(CCK)emia, reduced meal size and increased satiety ratio, and increased fecal energy content (measured at 8 weeks).

Conclusions Weight loss after VTPP, SG, or DS differed in terms of degree, duration, and underlying mechanisms. DS without SG was most effective in the long-term, probably due to hyperCCKemia-induced reduction in food intake and longlimb intestinal bypass-induced malabsorption.
\end{abstract}

Keywords Body weight · Food intake $\cdot$ Obesity surgery

Y. Kodama $\cdot$ C.-M. Zhao $\cdot$ B. Kulseng $\cdot$ D. Chen Department of Cancer Research and Molecular Medicine, Norwegian University of Science and Technology,

Trondheim, Norway

B. Kulseng

Departments of Surgery and Endocrinology,

St. Olavs University Hospital,

Trondheim, Norway

D. Chen $(\bowtie)$

Department of Cancer Research and Molecular Medicine, Faculty of Medicine,

Norwegian University of Science and Technology,

Laboratory Centre (3rd Floor-East Side),

Erling Skjalgssons Gate 1,

7006 Trondheim, Norway

e-mail: duan.chen@ntnu.no

\section{Introduction}

During the evolution of surgery for morbid obesity, many different surgical procedures have been developed in order to reduce food intake and/or nutrition absorption. For instance, gastric bypass surgery is designed to create a small pouch in the stomach to produce early satiety and a consequent reduction in food intake, and moreover to induce malabsorption by creating a short gut syndrome and/ or by accomplishing distal mixing of bile acid and pancreatic juice with ingested nutrients, thereby reducing absorption. It has also been demonstrated that weight loss surgery, including gastric bypass, changes the perception of food and thus eating behavior, leading to the concept of "behavior surgery". ${ }^{1}$ We recently reported that rats developed an altered eating behavior for the short term, but not the long term after gastric bypass. Gastric-bypassed rats ate more during the daytime than sham-operated control rats and were unable to keep up with the control rats with respect to meal size and eating rate during the night. More 
interestingly, neither their food intake nor absorption was reduced, despite the fact that the rats had a loss in body weight following the gastric bypass. ${ }^{2}$

Based on the hypothesis that "common obesity" has hypothalamic origins, truncal vagotomy was used for treatment of severe obesity. ${ }^{3}$ Based on the understanding that the vagus nerve controls satiety/hunger and energy homeostasis, an alternative minimally invasive treatment, the so-called "Vagal BLocking for Obesity Control" (VBLOC), has been developed to intermittently block vagal nerve trunks with high frequency and low power electrical signals through the laparoscopically implanted device. ${ }^{4}$ Hence, the first aim of the present study was to analyze the eating behavior and energy expenditure in rats subjected to bilateral truncal vagotomy. The measurements were performed by utilizing a state-of-the-art method known as a comprehensive laboratory animal metabolic monitoring system (CLAMS), as performed in our previous studies. ${ }^{2,5,6}$

Laparoscopically assisted vertical gastrectomy using a Dexterity Pneumo Sleeve device, the so-called sleeve gastrectomy, was originally proposed as the first stage followed by Roux-en-Y gastric bypass or duodenal switch as the second stage. ${ }^{7,8}$ This procedure has been recently considered as an independent weight loss surgery, based on clinical outcomes and presumably underlying mechanism in which the ghrelin-rich gastric fundus is eliminated and the volume of the stomach is reduced. ${ }^{9-12}$ Previously, we compared the eating behavior in rats that underwent a total gastrectomy vs. gastric bypass (i.e., end-to-end anastomosis of esophagus-proximal jejunum) and found that the food intake and meal size were reduced after gastrectomy but not gastric bypass, thus suggesting that the control of food intake was independent of the food reservoir function of the stomach. ${ }^{5}$ Therefore, the second aim of the present study was to analyze the eating behavior and energy expenditure in rats subjected to sleeve gastrectomy.

The duodenal switch procedure was originally created as a surgical solution for primary bile reflux gastritis and/or to decrease post-gastrectomy symptoms after distal gastrectomy and gastroduodenostomy. ${ }^{13}$ Currently, a combined procedure of sleeve gastrectomy and duodenal switch has been applied to the treatment of morbid obesity based on the rationale that the sleeve gastrectomy preserves the pylorus and first portion of the duodenum which negates the possibility of dumping symptoms and reduces the risk of marginal ulcers. ${ }^{8}$ The duodenal switch procedure achieves complete pancreaticobiliary diversion. As a result, postprandial biliary and pancreatic secretion will be reduced or eliminated, and the negative feedback effect of the bile acid and pancreatic juice on cholecystokinin (CCK)-producing cells in the duodenum and jejunum will be deprived, thereby leading to an increase in circulating CCK levels. Since CCK is well known as a satiety hormone, we hypothesized that the duodenal switch procedure could be an independent weight loss surgery because this procedure would reduce the food intake due to hyperCCKemia and induce malabsorption due to long-limb intestinal bypass. Hence, the third aim of the present study was to evaluate the effects of a duodenal switch with and without a sleeve gastrectomy on body weight, eating behavior, serum CCK levels, fecal energy content, and energy expenditure.

\section{Materials and Methods}

\section{Animals}

Male rats (Sprague-Dawley, 3 months old) were purchased from Taconic M\&B, Skensved, Denmark. The males were preferred because females change their food intake during ovulation and males grow faster than females, making it easier to detect body weight change. The rats were housed in individually ventilated Makrolon cages with $12 \mathrm{~h} \mathrm{light/}$ dark cycle, room temperature of $22^{\circ} \mathrm{C}$ and $40-60 \%$ relative humidity. They were allowed free access to tap water and standard rat pellet food (RM1 801002, Scanbur BK AS, Sweden). The study was approved by the Norwegian National Animal Research Authority (Forsøksdyrutvalget, FDU).

\section{Experimental Design}

The animals were divided into the following groups: laparotomy (LAP), pyloroplasty (PP), bilateral truncal vagotomy plus pyloroplasty (VTPP), sleeve gastrectomy (SG), duodenal switch alone (DS), SG as the first stage and then DS as the second stage $\left(\mathrm{SG}_{1}+\mathrm{DS}_{2}\right)$, and $\mathrm{SG}$ and $\mathrm{DS}$ simultaneously ( $\mathrm{SG}+\mathrm{DS})$. In consideration of the "3Rs" for the human use of animals (e.g., reduction of animal numbers to the minimum consistent with achieving the scientific purposes of the experiment),${ }^{14}$ rats in control groups have been re-used after a 9-week recovery from previous operation and revealed an unchanged eating behavior and metabolic parameters. The rats were first subjected to LAP $(n=7)$, PP $(n=7)$, or VTPP $(n=7)$, respectively. After 9 weeks, LAP and PP rats were subjected to SG and DS, respectively. After an additional 11 weeks, SG rats were subjected to DS, and VTPP rats were simultaneously subjected to both SG and DS. An additional group of agematched rats were subjected to LAP $(n=7)$.

Each rat was monitored weekly with respect to the body weight development throughout the study period. Each rat was placed in the CLAMS cage three times for $48 \mathrm{~h}$, i.e., 1 week before surgery, 1-2 and 8-11 weeks after surgery for measurements of the eating and metabolic parameters. 

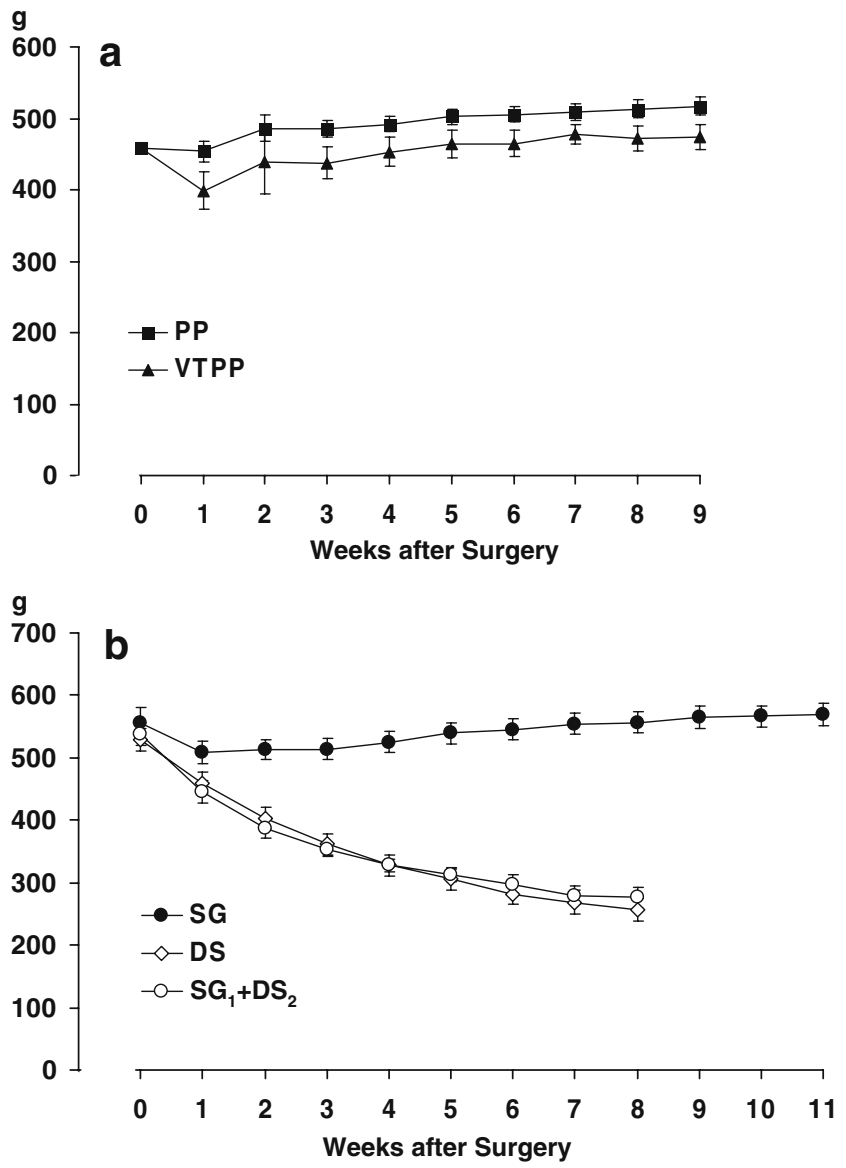

Fig. 1 Body weight developments after pyloroplasty (PP) and bilateral truncal vagotomy plus pyloroplasty (VTPP) (a), and after sleeve gastrectomy (SG), duodenal switch alone (DS) and SG as the first stage and then DS as the second stage $\left(\mathrm{SG}_{1+} \mathrm{DS}_{2}\right)(\mathbf{b})$. Data are expressed as mean $\pm \mathrm{SEM}$

\section{Surgery}

Rats were deprived of food but not water for $12 \mathrm{~h}$ pre- and $24 \mathrm{~h}$ post-operation. All operations were performed under general anesthesia with isofluran (4\% for induction and $2 \%$ for maintenance). Buprenorphine $(0.05 \mathrm{mg} / \mathrm{kg})$ was administrated as a pain reliever subcutaneously immediately after surgery. LAP was performed through middle-line incision. PP was performed by cutting off the pyloric sphincter ( $2 \mathrm{~mm}$ ) and suturing it vertically against the incision. VTPP was achieved by cutting both the anterior and posterior vagal trunks immediately below the diaphragm and, while at the same time performing a PP to prevent gastroparesisinduced food retention and gastric dilation. SG was performed by resecting $70 \%$ of the glandular stomach along the greater curvature. DS was constructed by transecting the duodenum $1 \mathrm{~cm}$ to the pylorus, and a common channel was created by dividing the ileum $5 \mathrm{~cm}$ proximal to the ileocecal junction (rats have a much longer jejunum than humans). The distal limb of the ileum was anastomosed to the post-pyloric duodenum in an end-to-end manner, and the stump of the duodenum was closed with cross-suture. The distal anastomosis was performed by joining the distal biliopancreatic limb at $1 \mathrm{~cm}$ to the ileocecal junction in an end-to-side manner.

Eating and Metabolic Parameters

Eating and metabolic parameters were automatically recorded by the comprehensive laboratory animal monitoring system (CLAMS; Columbus Instruments International, Columbus, OH, USA). This system is composed of a fourchamber indirect calorimeter designed for the continuous monitoring of individual rats from each chamber. An air sample was withdrawn every $5 \mathrm{~min}$. The energy expenditure $(\mathrm{kcal} / \mathrm{h})$ was calculated according to equation: $(3.815+$ $1.232 \mathrm{RER}) \times \mathrm{VO}_{2}$, where the respiratory exchange ratio (RER) was the volume of $\mathrm{CO}_{2}$ produced per volume of $\mathrm{O}_{2}$ consumed. $\mathrm{VO}_{2}$ was the volume of $\mathrm{O}_{2}$ consumed per hour per kilogram of mass of the animal. The energy expenditure is expressed as $\mathrm{kcal} / \mathrm{h} / 100 \mathrm{~g}$ body weight. Urine production was automatically recorded by weight. In order for rats to acclimate to this system, they were placed in these metabolic cages for $24 \mathrm{~h}$ before the first CLAMS monitoring. The high-resolution eating data was generated by monitoring all eating balances every $0.5 \mathrm{~s}$, providing accumulated food intake, meal size, and meal duration. The end of an eating event (meal) was when the balance was stable for more than $10 \mathrm{~s}$ and a minimum of $0.05 \mathrm{~g}$ was
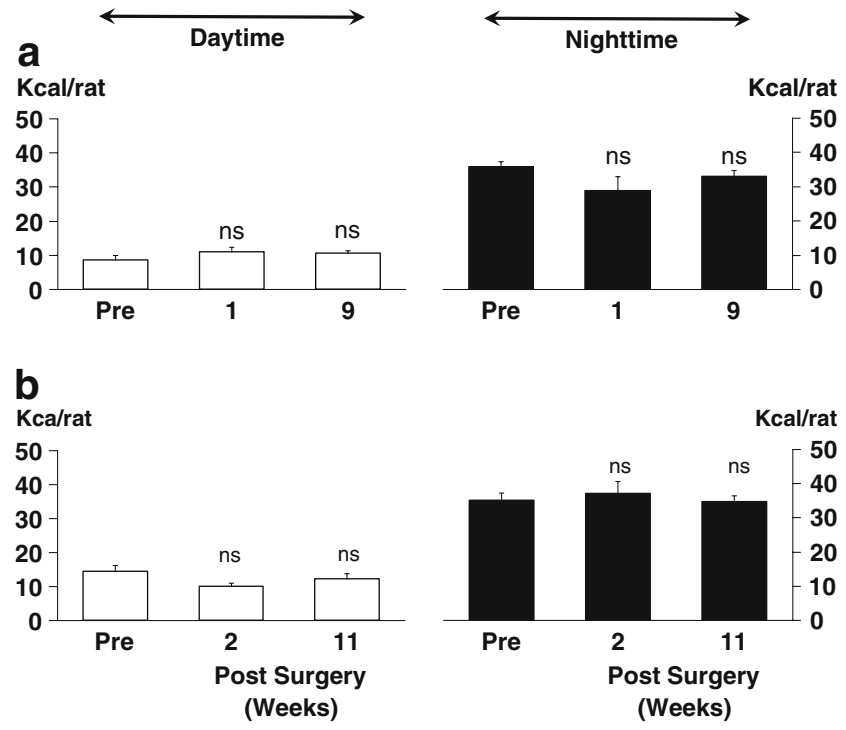

Fig. 2 Calories intake ( $\mathrm{kcal} / \mathrm{rat})$ during the day and the night at 1 week before (Pre), 1 and 9 weeks after bilateral truncal vagotomy plus pyloroplasty (VTPP) (a), 1 week before (Pre), 2 and 11 weeks after sleeve gastrectomy (SG) (b). Data are expressed as mean $\pm \mathrm{SEM}$. $n s$ not significant between pre- vs. post-operation 
eaten. Parameters during daytime and nighttime for each rat included: meal size, meal duration, accumulated food intake, intermeal interval, rate of eating, and satiety ratio. The intermeal interval was defined as the interval in minutes between two meals. The rate of eating was calculated by dividing meal size by meal duration. The satiety ratio, an index of non-eating time produced by each gram of food consumed, was calculated as intermeal interval divided by meal size. The rats were placed in the CLAMS chambers for $48 \mathrm{~h}$ (data from the first $24 \mathrm{~h}$ were not used in the analysis) with free access to standard rat powder food (RM1 811004, Scanbur BK AS, Sweden) and tap water. The total metabolizable energy was $2.57 \mathrm{kcal} / \mathrm{g}$ for both RM1 801002 and 811004 .

\section{Determination of Energy Content in Feces}

Feces were collected when the rats were placed in CLAMS cages 8 weeks after DS or age-matched control
LAP, and dried for $72 \mathrm{~h}$ at $60^{\circ} \mathrm{C}$. The energy content was determined by means of an adiabatic bomb calorimeter (IKA-Calorimeter C 5000, IKA-Werke GmbH \& Co. KG, Staufen, Germany).

\section{Determination of Serum CCK Levels}

CCK levels in serum were analyzed by radioimmunoassay with sulfated CCK-8 as standard, using a CCK kit (Eurodiagnostica AB, Malmö, Sweden).

\section{Statistical Analysis}

The data were expressed as mean \pm SEM. Comparisons between surgical groups and between three time points (1 week before, 1-2 and 8-11 weeks after surgery) were performed using an independent sample $t$ test or ANOVA followed by a Tukey's test when applicable. $p<0.05$ was considered statistically significant.

Table 1 Eating and metabolic parameters at 1 week before VTPP, 1 and 9 weeks after VTPP

\begin{tabular}{|c|c|c|c|c|}
\hline & Parameters & $1 \mathrm{~W}$ before VTPP & $1 \mathrm{~W}$ after VTPP & $9 \mathrm{~W}$ after VTPP \\
\hline \multirow[t]{10}{*}{ Daytime } & Food intake $(\mathrm{g})$ & $3.37 \pm 0.51$ & $4.27 \pm 0.53 \mathrm{~ns}$ & $4.08 \pm 0.31 \mathrm{~ns}$ \\
\hline & Food intake (g/100 g body weight) & $0.74 \pm 0.11$ & $1.11 \pm 0.18 \mathrm{~ns}$ & $0.86 \pm 0.07 \mathrm{~ns}$ \\
\hline & Calories intake (kcal) & $8.66 \pm 1.30$ & $10.97 \pm 1.37 \mathrm{~ns}$ & $10.49 \pm 0.79 \mathrm{~ns}$ \\
\hline & Calories intake (kcal/100 g body weight) & $1.91 \pm 0.29$ & $2.86 \pm 0.46 \mathrm{~ns}$ & $2.20 \pm 0.18 \mathrm{~ns}$ \\
\hline & Number of meals & $13.86 \pm 1.77$ & $12.43 \pm 1.73 \mathrm{~ns}$ & $15.57 \pm 1.95 \mathrm{~ns}$ \\
\hline & Meal size (g/meal) & $0.25 \pm 0.03$ & $0.39 \pm 0.07 \mathrm{~ns}$ & $0.28 \pm 0.03 \mathrm{~ns}$ \\
\hline & Meal duration (min/meal) & $1.00 \pm 0.20$ & $1.81 \pm 0.52 \mathrm{~ns}$ & $1.12 \pm 0.14 \mathrm{~ns}$ \\
\hline & Intermeal interval (min) & $51.86 \pm 6.11$ & $59.91 \pm 10.49 \mathrm{~ns}$ & $46.82 \pm 6.47 \mathrm{~ns}$ \\
\hline & Satiety ratio $(\mathrm{min} / \mathrm{g})$ & $230.76 \pm 43.10$ & $165.10 \pm 20.64 \mathrm{~ns}$ & $166.71 \pm 13.47 \mathrm{~ns}$ \\
\hline & Rate of eating (g/min) & $0.27 \pm 0.02$ & $0.27 \pm 0.04 \mathrm{~ns}$ & $0.26 \pm 0.02 \mathrm{~ns}$ \\
\hline \multirow[t]{10}{*}{ Nighttime } & Food intake $(\mathrm{g})$ & $13.90 \pm 0.63$ & $11.18 \pm 1.61 \mathrm{~ns}$ & $12.80 \pm 0.70 \mathrm{~ns}$ \\
\hline & Food intake ( $\mathrm{g} / 100 \mathrm{~g}$ body weight) & $3.06 \pm 0.15$ & $2.72 \pm 0.26 \mathrm{~ns}$ & $2.68 \pm 0.14 \mathrm{~ns}$ \\
\hline & Calories intake (kcal) & $35.72 \pm 1.62$ & $28.73 \pm 4.14 \mathrm{~ns}$ & $32.89 \pm 1.80 \mathrm{~ns}$ \\
\hline & Calories intake (kcal/100 g body weight) & $7.87 \pm 0.39$ & $6.99 \pm 0.66 \mathrm{~ns}$ & $6.88 \pm 0.36 \mathrm{~ns}$ \\
\hline & Number of meals & $31.00 \pm 3.04$ & $24.29 \pm 3.02 \mathrm{~ns}$ & $31.00 \pm 5.32 \mathrm{~ns}$ \\
\hline & Meal size (g/meal) & $0.46 \pm 0.03$ & $0.48 \pm 0.06 \mathrm{~ns}$ & $0.50 \pm 0.10 \mathrm{~ns}$ \\
\hline & Meal duration (min/meal) & $1.96 \pm 0.29$ & $2.64 \pm 0.46 \mathrm{~ns}$ & $2.12 \pm 0.32 \mathrm{~ns}$ \\
\hline & Intermeal interval (min) & $21.78 \pm 1.92$ & $29.97 \pm 5.48 \mathrm{~ns}$ & $25.66 \pm 5.36 \mathrm{~ns}$ \\
\hline & Satiety ratio $(\mathrm{min} / \mathrm{g})$ & $46.70 \pm 2.27$ & $65.33 \pm 10.13 \mathrm{~ns}$ & $50.59 \pm 2.40 \mathrm{~ns}$ \\
\hline & Rate of eating (g/min) & $0.25 \pm 0.02$ & $0.20 \pm 0.03 \mathrm{~ns}$ & $0.24 \pm 0.02 \mathrm{~ns}$ \\
\hline \multirow[t]{3}{*}{$24 \mathrm{~h}$} & Energy expenditure $(\mathrm{kcal} / \mathrm{h} / 100 \mathrm{~g}$ body weight) & $0.39 \pm 0.01$ & $0.43 \pm 0.01 \mathrm{~ns}$ & $0.36 \pm 0.01 *$ \\
\hline & RER & $0.95 \pm 0.01$ & $0.93 \pm 0.01 \mathrm{~ns}$ & $0.95 \pm 0.01 \mathrm{~ns}$ \\
\hline & Ambulatory activity & $7,494.14 \pm 1,240.97$ & $6,902.00 \pm 923.12 \mathrm{~ns}$ & $6,504.00 \pm 999.08 \mathrm{~ns}$ \\
\hline
\end{tabular}

Data are expressed as mean \pm SEM

$n s$ not significant

$* p<0.01(1 \mathrm{~W}$ vs. $9 \mathrm{~W})$ 


\section{Results}

Mortality

There was no mortality in rats that underwent LAP, PP, or VTPP. The mortality rate was one of seven in rats subjected to $\mathrm{SG}$, two of seven to $\mathrm{DS}$ alone, one of six to $\mathrm{SG}_{1}+\mathrm{DS}_{2}$, and six of seven to $\mathrm{SG}+\mathrm{DS}$ simultaneously.

\section{Body Weight}

Both LAP and PP had no effect on body weight development. VTPP transiently reduced the body weight (about $10 \%$ at 1 week postoperatively; Fig. 1a). SG reduced the body weight (approximately 10\%) for about 6 weeks (Fig. 1b). DS alone or SG followed by DS reduced the body weight in a similar manner: a rapid and continuous weight loss of about $10 \%$ at 1 week and $50 \%$ at 8 weeks postoperatively (Fig. 1b).
Food Intake, Eating Behavior, Energy Expenditure, and Fecal Energy Content

Food intake was higher and the satiety ratio was lower during the night than the day for each rat.

There were no differences between LAP and PP in terms of food intake and eating behavior parameters at either 1 or 9 weeks postoperatively (data not shown).

VTPP was without any measurable effects on food intake, eating behavior, and metabolic parameters measured at either 1 or 9 weeks postoperatively (Fig. 2a; Table 1).

SG had no effects on food intake and eating behavior parameters, except for meal duration during the night measured at 2 weeks (Fig. 2b; Table 2). In addition, SG reduced the water intake during one interval $(0.91 \pm 0.07$ vs. $0.47 \pm 0.07 \mathrm{~mL}$ at 2 weeks and vs. $0.45 \pm 0.08 \mathrm{~mL}$ at 11 weeks, both $p<0.01)$. Energy expenditure was increased at 2 weeks and RER was increased at 11 weeks postoperatively (Table 2).

Table 2 Eating and metabolic parameters at 1 week before SG, 2 and 11 weeks after SG

\begin{tabular}{|c|c|c|c|c|}
\hline & Parameters & $1 \mathrm{~W}$ before $\mathrm{SG}$ & $2 \mathrm{~W}$ after $\mathrm{SG}$ & $11 \mathrm{~W}$ after $\mathrm{SG}$ \\
\hline \multirow[t]{10}{*}{ Daytime } & Food intake $(\mathrm{g})$ & $5.62 \pm 0.70$ & $3.92 \pm 0.38 \mathrm{~ns}$ & $4.76 \pm 0.63 \mathrm{~ns}$ \\
\hline & Food intake (g/100 g body weight) & $1.01 \pm 0.15$ & $0.77 \pm 0.07 \mathrm{~ns}$ & $0.83 \pm 0.10 \mathrm{~ns}$ \\
\hline & Calories intake (kcal) & $14.43 \pm 1.79$ & $10.08 \pm 0.97 \mathrm{~ns}$ & $12.24 \pm 1.62 \mathrm{~ns}$ \\
\hline & Calories intake (kcal/100 g body weight) & $2.60 \pm 0.38$ & $1.97 \pm 0.18 \mathrm{~ns}$ & $2.13 \pm 0.27 \mathrm{~ns}$ \\
\hline & Number of meals & $13.83 \pm 1.83$ & $9.83 \pm 1.42 \mathrm{~ns}$ & $11.17 \pm 1.54 \mathrm{~ns}$ \\
\hline & Meal size (g/meal) & $0.41 \pm 0.01$ & $0.44 \pm 0.08 \mathrm{~ns}$ & $0.43 \pm 0.04 \mathrm{~ns}$ \\
\hline & Meal duration (min/meal) & $1.52 \pm 0.13$ & $1.72 \pm 0.20 \mathrm{~ns}$ & $1.29 \pm 0.07 \mathrm{~ns}$ \\
\hline & Intermeal interval (min) & $51.45 \pm 7.09$ & $70.24 \pm 8.34 \mathrm{~ns}$ & $62.28 \pm 7.13 \mathrm{~ns}$ \\
\hline & Satiety ratio $(\mathrm{min} / \mathrm{g})$ & $124.13 \pm 14.28$ & $170.13 \pm 18.28 \mathrm{~ns}$ & $149.69 \pm 23.39 \mathrm{~ns}$ \\
\hline & Rate of eating ( $\mathrm{g} / \mathrm{min})$ & $0.28 \pm 0.02$ & $0.25 \pm 0.03 \mathrm{~ns}$ & $0.33 \pm 0.02 \mathrm{~ns}$ \\
\hline \multirow[t]{10}{*}{ Nighttime } & Food intake $(\mathrm{g})$ & $13.61 \pm 0.89$ & $14.41 \pm 1.39 \mathrm{~ns}$ & $13.47 \pm 0.69 \mathrm{~ns}$ \\
\hline & Food intake (g/100 g body weight) & $2.43 \pm 0.17$ & $2.80 \pm 0.22 \mathrm{~ns}$ & $2.34 \pm 0.09 \mathrm{~ns}$ \\
\hline & Calories intake (kcal) & $34.97 \pm 2.28$ & $37.04 \pm 3.57 \mathrm{~ns}$ & $34.63 \pm 1.78 \mathrm{~ns}$ \\
\hline & Calories intake (kcal/100 g body weight) & $6.23 \pm 0.43$ & $7.19 \pm 0.56 \mathrm{~ns}$ & $6.01 \pm 0.22 \mathrm{~ns}$ \\
\hline & Number of meals & $28.50 \pm 3.40$ & $23.17 \pm 3.59 \mathrm{~ns}$ & $28.00 \pm 4.27 \mathrm{~ns}$ \\
\hline & Meal size (g/meal) & $0.50 \pm 0.06$ & $0.73 \pm 0.15 \mathrm{~ns}$ & $0.53 \pm 0.07 \mathrm{~ns}$ \\
\hline & Meal duration (min/meal) & $1.69 \pm 0.19$ & $2.88 \pm 0.47^{*}$ & $1.77 \pm 0.18 \mathrm{~ns}$ \\
\hline & Intermeal interval (min) & $24.46 \pm 2.86$ & $31.58 \pm 5.83 \mathrm{~ns}$ & $26.76 \pm 5.05 \mathrm{~ns}$ \\
\hline & Satiety ratio $(\mathrm{min} / \mathrm{g})$ & $48.93 \pm 3.63$ & $45.93 \pm 4.93 \mathrm{~ns}$ & $48.68 \pm 2.50 \mathrm{~ns}$ \\
\hline & Rate of eating (g/min) & $0.30 \pm 0.00$ & $0.25 \pm 0.02 \mathrm{~ns}$ & $0.30 \pm 0.01 \mathrm{~ns}$ \\
\hline \multirow[t]{3}{*}{$24 \mathrm{~h}$} & Energy expenditure $(\mathrm{kcal} / \mathrm{h} / 100 \mathrm{~g}$ body weight) & $0.34 \pm 0.01$ & $0.38 \pm 0.00^{*}$ & $0.37 \pm 0.01 \mathrm{~ns}$ \\
\hline & RER & $0.96 \pm 0.01$ & $0.94 \pm 0.01 \mathrm{~ns}$ & $1.02 \pm 0.01 * *, * * *$ \\
\hline & Ambulatory activity & $7,014.50 \pm 1,001.57$ & $6,721 \cdot 17 \pm 807.00 \mathrm{~ns}$ & $5,094.67 \pm 549.75 \mathrm{~ns}$ \\
\hline
\end{tabular}

Data are expressed as mean \pm SEM

$n s$ not significant

$* p<0.05$

${ }^{* *} p<0.01$ (pre vs. $2 \mathrm{~W}$ or $11 \mathrm{~W}$ )

$* * * p<0.01$ ( $2 \mathrm{~W}$ vs.11 W) 
DS regardless of whether it was accompanied by SG reduced the daily food/calories intake by approximately $50 \%$ when measured at 2 as well as 8 weeks postoperatively (Fig. 3a; Table 3). The reduced food intake was associated with a reduced meal size and an increased satiety ratio, but not with the number of meals (Fig. 3b-d; Table 3). The fecal energy content of DS rats was higher than that of control LAP rats $(20411.15 \pm 177.86 \mathrm{~J} / \mathrm{g}$ vs. $18756.36 \pm 51.61 \mathrm{~J} / \mathrm{g}$, $p<0.001)$ at 8 weeks. It was difficult to collect the feces at 2 weeks after DS due to a severe diarrhea. There were no differences between DS and $\mathrm{SG}_{1}+\mathrm{DS}_{2}$ in terms of food intake and eating behavior parameters, except RER and energy expenditure at 2 weeks and water intake at 8 weeks postoperatively.
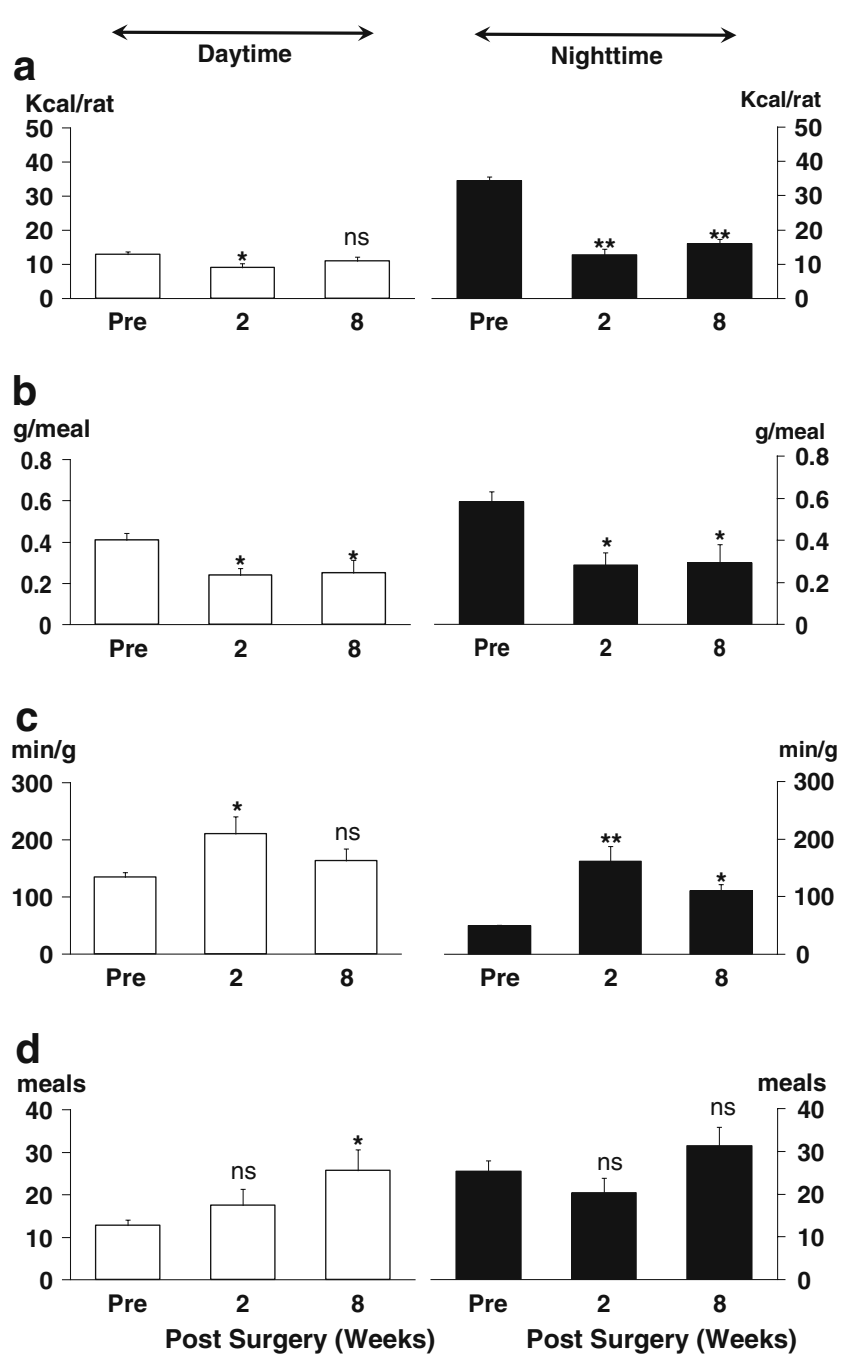

Fig. 3 Calories intake (kcal/rat) (a), meal size (g/meal) (b), satiety ratio(min/g) (c), number of meals (meals) (d) during the day and the night at 1 week before (Pre), 2 and 8 weeks after duodenal switch (DS)(regardless of whether it was accompanied by SG). Data are expressed as mean \pm SEM. ${ }^{*} p<0.05, * * p<0.01, n s$ not significant between pre- vs. $2 \mathrm{~W}$ or $8 \mathrm{~W}$ postoperatively
One surviving rat that was subjected to $\mathrm{SG}+\mathrm{DS}$ had reduced food intake and altered eating behavior, much like the rats subjected to $\mathrm{SG}_{1}+\mathrm{DS}_{2}$. However, this was not analyzed statistically.

\section{Circulating CCK Levels}

Serum CCK levels were $12.6 \pm 3.0 \mathrm{pmol} / \mathrm{L}$ in $\mathrm{SG}_{1}+\mathrm{DS}_{2}$ rats. This was more than ten times higher than the value of rats subjected to the sham operation in our previous report (plasma CCK levels were $1.1 \pm 0.5 \mathrm{pmol} / \mathrm{L}$ ). ${ }^{15}$ Unfortunately, there was a technical error in the determination of the CCK levels in age-matched control LAP and DS rats in the present study.

\section{Discussion}

The role of vagus in physiologically controlling eating behavior has been studied during the past decades. It is believed that food interacts with the gut to provide the brain via vagal afferents with information regarding food composition, amount of ingested food and energy content. The brain determines the rate of nutrient absorption, partitioning, storage, and mobilization through vagal efferents as well as the sympathetic nervous system and hormonal mechanisms. ${ }^{16}$ This food-gut-brain axis is considered as an autonomic neurohumoral pathway regulating energy homeostasis. In the present study, disruption of the gut-brain axis by VTPP was without any measureable effect on the energy homeostasis. The body weight loss was slight (about $15 \%)$ and transient (1 week postoperatively). This may explain why vagotomy as treatment for obesity has received little attention since it was used 30 years ago. ${ }^{3}$ However, with the substantial need for effective treatment of obesity at younger ages and the improved safety of laparoscopic procedures, it has been suggested that surgical treatment can be justified at lower levels of BMI, before the eating disorder has become intractable and requires malabsorptive operations. The possibility for utilizing a laparoscopic abdominal vagotomy has been well discussed elsewhere. ${ }^{17}$

SG weight loss surgery is believed to be restrictive as well as a neurohormone-mediated procedure. The early clinical results seem promising, but long-term data is still needed to define the place of LSG within the bariatric surgery armamentarium. ${ }^{18,19}$ In the present study, SG reduced the body weight by about $10 \%$ in the short-term (1-6 weeks) but not in the long-term (after 7 weeks). The reduction was not associated with reduced food intake but possibly with increased energy expenditure, which is in line with previous observations in rats subjected to total gastrectomy or gastric bypass. ${ }^{5}$ The underlying physiological mechanisms are still unknown. It should also be 
Table 3 Eating and metabolic parameters at 1 week before DS both with and without SG, 2 and 8 weeks after DS both with and without SG

\begin{tabular}{|c|c|c|c|c|}
\hline & Parameters & $1 \mathrm{~W}$ before operation & $2 \mathrm{~W}$ after operation & $8 \mathrm{~W}$ after operation \\
\hline \multirow[t]{10}{*}{ Daytime } & Food intake (g) & $4.99 \pm 0.31$ & $3.54 \pm 0.44^{*}$ & $4.30 \pm 0.44 \mathrm{~ns}$ \\
\hline & Food intake ( $\mathrm{g} / 100 \mathrm{~g}$ body weight) & $0.92 \pm 0.05$ & $0.87 \pm 0.11 \mathrm{~ns}$ & $1.60 \pm 0.20 * *, * * * *$ \\
\hline & Calories intake (kcal) & $12.83 \pm 0.79$ & $9.11 \pm 1.14^{*}$ & $11.05 \pm 1.14 \mathrm{~ns}$ \\
\hline & Calories intake (kcal/100 g body weight) & $2.36 \pm 0.13$ & $2.25 \pm 0.28 \mathrm{~ns}$ & $4.10 \pm 0.51 * *, * * * *$ \\
\hline & Number of meals & $12.80 \pm 1.18$ & $17.50 \pm 3.79 \mathrm{~ns}$ & $25.70 \pm 4.86^{*}$ \\
\hline & Meal size (g/meal) & $0.41 \pm 0.03$ & $0.24 \pm 0.03 *$ & $0.25 \pm 0.06^{*}$ \\
\hline & Meal duration (min/meal) & $1.33 \pm 0.10$ & $2.35 \pm 0.41 \mathrm{~ns}$ & $3.74 \pm 1.82 \mathrm{~ns}$ \\
\hline & Intermeal interval (min) & $54.01 \pm 4.00$ & $54.86 \pm 14.48 \mathrm{~ns}$ & $42.19 \pm 12.04 \mathrm{~ns}$ \\
\hline & Satiety ratio $(\mathrm{min} / \mathrm{g})$ & $134.37 \pm 8.03$ & $210.35 \pm 29.60^{*}$ & $163.30 \pm 20.66 \mathrm{~ns}$ \\
\hline & Rate of eating ( $\mathrm{g} / \mathrm{min})$ & $0.31 \pm 0.01$ & $0.13 \pm 0.03 * *$ & $0.10 \pm 0.01 * *$ \\
\hline \multirow[t]{10}{*}{ Nighttime } & Food intake $(\mathrm{g})$ & $13.34 \pm 0.43$ & $4.89 \pm 0.73 * *$ & $6.16 \pm 0.54 * *$ \\
\hline & Food intake (g/100 g body weight) & $2.47 \pm 0.12$ & $1.19 \pm 0.17 * *$ & $2.20 \pm 0.15^{* * * *}$ \\
\hline & Calories intake (kcal) & $34.29 \pm 1.10$ & $12.56 \pm 1.86^{* *}$ & $15.82 \pm 1.38 * *$ \\
\hline & Calories intake (kcal/100 g body weight) & $6.35 \pm 0.30$ & $3.07 \pm 0.44 * *$ & $5.65 \pm 0.39 * * * *$ \\
\hline & Number of meals & $25.20 \pm 2.62$ & $20.30 \pm 3.43 \mathrm{~ns}$ & $31.20 \pm 4.48 \mathrm{~ns}$ \\
\hline & Meal size (g/meal) & $0.58 \pm 0.05$ & $0.28 \pm 0.06^{*}$ & $0.29 \pm 0.09^{*}$ \\
\hline & Meal duration (min/meal) & $1.96 \pm 0.19$ & $3.64 \pm 1.28 \mathrm{~ns}$ & $3.84 \pm 1.58 \mathrm{~ns}$ \\
\hline & Intermeal interval (min) & $28.19 \pm 2.96$ & $40.29 \pm 6.97 \mathrm{~ns}$ & $27.13 \pm 7.01 \mathrm{~ns}$ \\
\hline & Satiety ratio $(\mathrm{min} / \mathrm{g})$ & $48.90 \pm 1.66$ & $161.24 \pm 26.37 * *$ & $109.27 \pm 11.90^{*}$ \\
\hline & Rate of eating ( $\mathrm{g} / \mathrm{min})$ & $0.30 \pm 0.01$ & $0.10 \pm 0.01 * *$ & $0.09 \pm 0.01 * *$ \\
\hline \multirow[t]{3}{*}{$24 \mathrm{~h}$} & Energy expenditure $(\mathrm{kcal} / \mathrm{h} / 100 \mathrm{~g}$ body weight) & $0.37 \pm 0.01$ & $0.38 \pm 0.02 \mathrm{~ns}$ & $0.43 \pm 0.01 *, * * *$ \\
\hline & RER & $0.99 \pm 0.02$ & $0.90 \pm 0.03 \mathrm{~ns}$ & $1.11 \pm 0.07 * * * *$ \\
\hline & Ambulatory activity & $5,410.30 \pm 696.92$ & $5,773.60 \pm 891.92 \mathrm{~ns}$ & $3,533.70 \pm 618.31 \mathrm{~ns}$ \\
\hline
\end{tabular}

Data are expressed as mean \pm SEM

$n s$ not significant

${ }^{*} p<0.05$

$* * p<0.01$ (pre vs. $2 \mathrm{~W}$ or $8 \mathrm{~W}$ )

$* * * p<0.05$

$* * * * p<0.01(2 \mathrm{~W}$ vs. $8 \mathrm{~W})$

mentioned that SG rats, like totally gastrectomized rats, seemed to drink frequently postoperatively, probably owing to lower ghrelin and obestatin levels. 5,20,21

In the present study, DS alone and SG+DS exhibited well-matched postoperative effects on body weight, metabolic parameters and eating behavior, leading to a long lasting and effective body weight loss. More interestingly, the results of the present study support our hypothesis that the DS procedure per se could be considered as an independent weight loss surgery because this procedure reduces the food intake due to hyperCCKemia and induces malabsorption due to intestinal bypass. As expected after pancreaticobiliary diversion, ${ }^{15,22-24}$ circulating CCK levels were elevated after $\mathrm{SG}_{1}+\mathrm{DS}_{2}$, which in turn increased the satiety ratio and reduced meal size. Malabsorption is believed to be due to long-limb intestinal bypass after DS. In fact, DS patients also showed a decreased appetite and continuously body weight loss. ${ }^{25}$ In addition to CCK, glucagon-like peptide-1 (GLP-1) levels in the circulation have been reported to be elevated in rats subjected to pancreaticobiliary diversion, which could have a beneficial effect on $\beta$ cells in the pancreas. ${ }^{26,27}$ Unfortunately, GLP-1 was not measured in the present study, thus it will be of interest for future study.

In conclusion, VTPP, SG, and DS, like gastric bypass, reduced the body weight, though the effectiveness and underlying mechanisms appear different. Since obesity is believed to a multifactorial disease, the options for the treatment, including various surgical procedures, should be individualized.

Acknowledgments The authors thank Dr. Catia Martins for determination of CCK levels, Jostein Johansen for assistance of data analysis at Department of Cancer Research and Molecular Medicine, and Morten Grønli, and Erik Langørgen for assistance of bomb calorimeter at Department of Energy and Process Engineering, Norwegian University of Science and Technology. 
Open Access This article is distributed under the terms of the Creative Commons Attribution Noncommercial License which permits any noncommercial use, distribution, and reproduction in any medium, provided the original author(s) and source are credited.

\section{References}

1. Miras AD, le Roux CW. Bariatric surgery and taste: novel mechanisms of weight loss. Curr Opin Gastroenterol. 2010;26(2):140-5.

2. Furnes MW, Tømmerås K, Arum CJ, Zhao CM, Chen D. Gastric bypass surgery causes body weight loss without reducing food intake in rats. Obes Surg. 2008;18(4):415-22.

3. Kral JG. Vagotomy for treatment of severe obesity. Lancet. 1978;1 (8059):307-8

4. Camilleri M, Toouli J, Herrera MF, Kulseng B, Kow L, Pantoja JP, Marvik R, Johnsen G, Billington CJ, Moody FG, Knudson $\mathrm{MB}$, Tweden KS, Vollmer M, Wilson RR, Anvari M. Intraabdominal vagal blocking (VBLOC therapy): clinical results with a new implantable medical device. Surgery. 2008;143(6):723-31.

5. Furnes MW, Stenstrom B, Tømmerås K, Skoglund T, Dickson SL, Kulseng B, Zhao CM, Chen D. Feeding behavior in rats subjected to gastrectomy or gastric bypass surgery. Eur Surg Res. 2008;40 (3):279-88.

6. Furnes MW, Zhao CM, Chen D. Development of obesity is associated with increased calories per meal rather than per day. A study of high-fat diet-induced obesity in young rats. Obes Surg. 2009;19(10):1430-8.

7. Naitoh T, Gagner M. Laparoscopically assisted gastric surgery using dexterity pneumo sleeve. Surg Endosc. 1997;11(8):830-3.

8. Anthone GJ. The duodenal switch operation for morbid obesity. Surg Clin North Am. 2005;85(4):819-33

9. Rosen DJ, Dakin GF, Pomp A. Sleeve gastrectomy. Minerva Chir. 2009;64(3):285-95.

10. Rubino F, Schauer PR, Kaplan LM, Cummings DE. Metabolic surgery to treat type 2 diabetes: clinical outcomes and mechanisms of action. Annu Rev Med. 2010;61:393-411.

11. Bohdjalian A, Langer FB, Shakeri-Leidenmühler S, Gfrerer L, Ludvik B, Zacherl J, Prager G. Sleeve gastrectomy as sole and definitive bariatric procedure: 5-year results for weight loss and ghrelin. Obes Surg. 2010;20(5):535-40.

12. Abu-Jaish W, Rosenthal RJ. Sleeve gastrectomy: a new surgical approach for morbid obesity. Expert Rev Gastroenterol Hepatol. 2010;4(1):101-19.

13. DeMeester TR, Fuchs KH, Ball CS, Albertucci M, Smyrk TC, Marcus JN. Experimental and clinical results with proximal endto-end duodenojejunostomy for pathologic duodenogastric reflux. Ann Surg. 1987;206(4):414-26.

14. Russell WMS, Burch RL. The Principles of Humane Experimental Technique. London: Methuen \& Co. LTD. 1959.

15. Chen D, Nylander A-G, Rehfeld JF, Axelson J, Ihse I, Hakanson R. Does vagotomy affect the growth of the pancreas in the rat? Scand J Gastroenterol 1992;27:606-608.

16. Berthoud HR. The vagus nerve, food intake and obesity. Regul Pept. 2008;149(1-3):15-25.

17. Kral JG. Psychosurgery for obesity. Obes Facts. 2009;2(6):339-41.

18. Ward M, Prachand V. Surgical treatment of obesity. Gastrointest Endosc. 2009;70(5):985-90.

19. Frezza EE, Chiriva-Internati M, Wachtel MS. Analysis of the results of sleeve gastrectomy for morbid obesity and the role of ghrelin. Surg Today. 2008;38(6):481-3.

20. Samson WK, White MM, Price C, Ferguson AV. Obestatin acts in brain to inhibit thirst. Am J Physiol Regul Integr Comp Physiol. 2007;292(1):R637-43.
21. Hashimoto H, Fujihara H, Kawasaki M, Saito T, Shibata M, Otsubo H, Takei Y, Ueta Y. Centrally and peripherally administered ghrelin potently inhibits water intake in rats. Endocrinology. 2007;148(4):1638-47.

22. Chen D, Nylander AG, Rehfeld JF, Sundler F, Håkanson R. Hypercholecystokininemia produced by pancreaticobiliary diversion causes gastrin-like effects on enterochromaffin-like cells in the stomach of rats subjected to portacaval shunting or antrectomy. Scand J Gastroenterol. 1993;28(11):988-92.

23. Chen D, Andersson K, Iovanna JL, Dagorn JC, Håkanson R. Effects of hypercholecystokininemia produced by pancreaticobiliary diversion on pancreatic growth and enzyme mRNA levels in starved rats. Scand J Gastroenterol. 1993;28(4):311-4.

24. Chen D, Nylander AG, Norlén P, Håkanson R. Gastrin does not stimulate growth of the rat pancreas. Scand J Gastroenterol. 1996;31(4):404-10.

25. Marceau P, Hould FS, Simard S, Lebel S, Bourque RA, Potvin M, Biron S. Biliopancreatic diversion with duodenal switch. World J Surg. 1998;22(9):947-54.

26. Borg CM, le Roux CW, Ghatei MA, Bloom SR, Patel AG. Biliopancreatic diversion in rats is associated with intestinal hypertrophy and with increased GLP-1, GLP-2 and PYY levels. Obes Surg. 2007;17(9):1193-8.

27. Miazza BM, Widgren S, Chayvialle JA, Nicolet T, Loizeau E. Exocrine pancreatic nodules after long-term pancreaticobiliary diversion in rats. An effect of raised CCK plasma concentrations. Gut. 1987;28 Suppl:269-73.

\section{Discussant}

DR. THOMAS H. MAGNUSON (Baltimore, MD): I would like to thank Dr. Kodama and congratulate him on an excellent presentation, and he and his coauthors on an excellent manuscript. They have given us some important insights into how some these bariatric operations work from a metabolic perspective. This is an important topic, with the ultimate goal of better selecting the right operation for each individual patient.

They found, interestingly, that vagotomy alone or sleeve gastrectomy alone seemed to have little impact on weight loss or eating behavior, but the duodenal switch operation did have a dramatic impact on weight loss and also altered energy expenditure.

I have a couple quick questions.

First, with regards to your sleeve gastrectomy model, it looks like this didn't work very well, but yet there's other animal models, obese rats and mice for example, as well as our human clinical experience, showing that the sleeve works pretty well as an operation for weight loss. I wonder if you could comment briefly on why your results differ from that of others. Did you measure circulating levels of ghrelin, which has been implicated as being important in the function of the sleeve gastrectomy as an appetite suppressant?

The second question involves your duodenal switch model. It looks like these animals lost dramatic weight, but was this really a physiologic model? It seems like most of these animals had severe diarrhea and over 30 or $40 \%$ of your animals actually died in the study. Was this due to severe malnutrition? Did you measure nutritional parameters, such as serum albumin levels, to make sure this wasn't a model of severe protein calorie malnutrition contributing to the deaths and the severe diarrhea?

In addition, you measured CCK levels and postulated that that might be an effect of the duodenal switch and its impact on satiety, but did you think about measuring other GI peptides. GLP-1, adiponectin, NPY and PYY have all been implicated as being important to weight loss in animal models that bypass variable lengths of intestine.

Once again, I enjoyed your presentation. 


\section{Closing discussant}

DR. YOSUKE KODAMA: Thank you very much for your comments. In this study with normal rats, duodenal switch, but not vagotomy or sleeve gastrectomy, resulted in the dramatic weight loss. It will be of interest to repeat this study but with obese rats to see whether the effect differs. We did not measure ghrelin levels in this study, because we did not see a significant weight loss after the sleeve gastrectomy.

As reported in our manuscript, 2 of 7 rats died after duodenal switch procedure alone, and 1 of 6 rats died after sleeve gastrectomy as the first stage and duodenal switch as the second stage. Such mortality is generally acceptable in the experimental surgery with small animals. All survived animals from duodenal switch had severe diarrhea but it lasted only for a short time period (e.g. 2 weeks). We did not measure the serum albumin levels. In the case that the two procedures were performed at the same time, 6 of 7 rats died, which was most likely due to surgical trauma.

This was our first experimental study suggesting that duodenal switch alone might be used as an independent weight loss surgery. The underlying mechanism should be further investigated, for example, by measuring not only CCK but also other GI hormones as you have suggested. 